\title{
Medical museums
}

Medical museums: past, present, future

Samuel J.M.M. Alberti and Elizabeth

Hallam, editors

Royal College of Surgeons of England; 2013

$\mathrm{T}$ he medical museum was once a teaching resource as important to a medical school as its library. Although medical libraries remain a vital educational institution, most medical museums have become obsolete or extinct.

Reasons for why, when, and how this change occurred relate to changes in the educational role of gross pathology and anatomy, and are discussed in this collection of 17 brief but thoughtful essays by leading scholars and museologists from the United Kingdom, the United States and Europe. Samuel Alberti (Director of Museums and Archives, Royal College of Surgeons of England, London, UK) and Elizabeth Hallam (an anthropologist affiliated with Aberdeen and Oxford universities in the UK), the editors of Medical museums: past, present, future, can take pride in this richly illustrated and well-produced book.

Not only is the anthology a valuable learned contribution, it is a fitting tribute to the bicentennial of the Hunterian

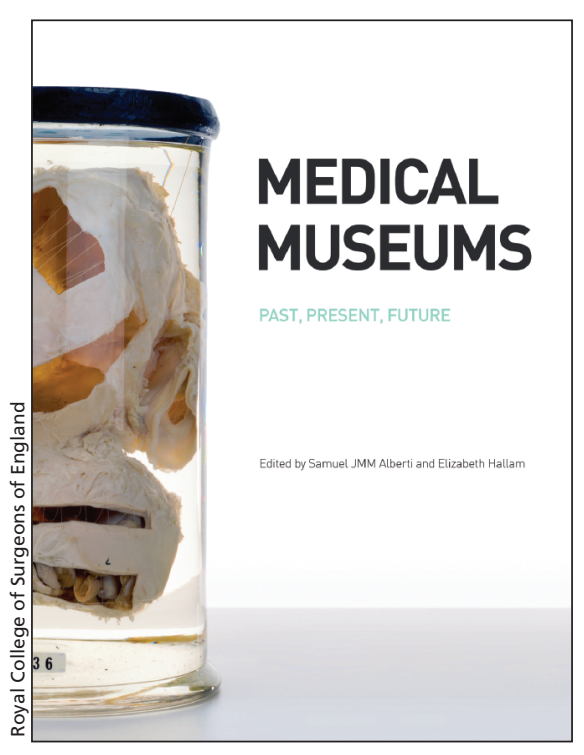

Gunther von Hagens' Body Worlds exhibits, for better or for worse, have piqued popular curiosity (or voyeurism) with respect to the display of normal and diseased body parts. For a deeper contextualization of the medical museum as an intellectual and cultural phenomenon, readers can take advantage of the book's helpful selected bibliography that identifies other related publications by many of the contributors.

Although many of the essays raise important museological issues in addition to describing the museums' individual

\section{The editors of Medical museums: past, present, future can take pride in this richly illustrated and well-produced book.}

Museum (part of the Royal College of Surgeons of England). The editors' jointly autographed Royal College bookplate in each volume is a delightful keepsake to remind readers of this event. Although the Hunterian Museum continues in its longstanding role as an educational resource for clinicians, like other medical museums, it is enjoying a renaissance by opening its doors to the wider community. As several of the essays show, such engagement was not unheard of in the past, but the likes of collections, several focus on specific facets of medical curatorship: bodies, morbid anatomy and the "post-medical museum." Thus, this anthology should interest a wide audience within the medical history community, and many physicians and surgeons may also be intrigued by it. Practitioners who span the clinical disciplines and biomedical sciences, such as anatomists and pathologists, will also profit greatly by reading it. The book's appeal rests on its range and readability. Accessible and informative essays about the Royal College of Surgeons' collections in both England and Edinburgh, the rise and fall of the anatomical collection in the University of Aberdeen and pertinent collections of London's Science Museum describe cardinal British institutions. Iconic European museums such as "La Specola" in Florence, Italy, the Karolinska Institute in Stockholm, Sweden, and the anatomical museum of Leiden, the Netherlands, are similarly featured, as are American museums such as the National Museum of Health and Medicine and the Smithsonian Institution's National Museum of American History, both in or near Washington, D.C.

Astute Canadian readers will notice one gap: there is no mention of the rise, decline and rebirth of the anatomical museum at McGill University in Montréal, Quebec, nor of its renowned curator, Dr. Maude Abbott (1869-1940). The modest beginnings of that collection date to the early $1820 \mathrm{~s}$, but received a boost through the preparation of many wet specimens by William Osler while he was pathologist at McGill in the later 19th century. At the turn of the 20th century, Abbott assumed curatorial duties and, in 1906, cofounded the International Association of Medical Museums (IAMM) in Washington, D.C., the organization devoted to the affairs and promotion of medical museums. The IAMM would later morph into the International Academy of Pathology, which stimulated interest in reconstituting the remains of McGill's collection to become the Maude Abbott Medical Museum in 2012. Should there ever be a subsequent edition of Medical museums: past, present, future, an essay about the Abbott collection would be a wonderful and welcome addition.

\section{J.T.H. Connor PhD}

John Clinch Professor of Medical

Humanities and History of Medicine

Faculty of Medicine

Memorial University

St. John's, NL

CMAJ 2014. DOI:10.1503/cmaj.131392 